\title{
AC 2007-2033: DEVELOPMENT OF AN OUTCOMES-BASED ASSESSMENT INSTRUMENT FOR USE BY THE SUPERVISORS OF PROFESSIONAL PRACTICE STUDENTS
}

\section{Robert Stwalley, Purdue University}

Robert M. Stwalley III, Ph.D., P.E. is the Director of the Purdue University Office of Professional Practice. Dr. Stwalley has been involved in education for over twenty years at three different institutions of higher education. He is currently the President of the Lafayette School Corporation Board of Trustees. Dr. Stwalley maintains a private consulting practice where he specializes in renewable energy projects and property transfer issues. He is married to Dr. Carol S. Stwalley, and they have four children: Kathryn, Robert IV, Elizabeth, and Daniel. 


\section{Development of an Outcomes-Based Assessment Instrument For Use by Supervisors of Professional Practice Students}

Abstract

The Purdue University Office of Professional Practice has been evaluating the performance of Cooperative Education students in the work place since its inception, and the current supervisors' evaluation instrument is on paper and has been in use at least since the present Director was himself a Purdue undergraduate engineering Co-Op student in the mid-1970's. Although the present evaluation forms are a reasonable and decent attempt to collect data on performance outcomes, the available aggregate data is both incomplete in depth and spotty in coverage. Unfortunately within a decentralized system, much of the work involved in collecting and analyzing this information has traditionally fallen to the various academic units. This work may be neglected, is difficult to collect by the central office and correlate, and may be of such small sample size so as to prove irrelevant within the specific department. To solve these deficiencies and upgrade the overall level of assessment, the Office of Professional Practice is designing a new instrument that will utilize an electronic means for collection. The performance evaluations will directly address our success at meeting ABET ${ }^{1,2}$ Criterion III requirements, The NAE Engineer of $2020^{3}$ guidelines, and our Purdue vision for The Future Engineer ${ }^{4}$. Although it will be the student's responsibility to see that their supervisor completes the evaluation, we are specifically designing the process to be minimally intrusive to insure a high rate of completion. The Purdue evaluation process will utilize some of the techniques pioneered by Mickelson and Hanneman ${ }^{5,6,7}$ at Iowa State University and Cedercreutz and Cates ${ }^{8}$ at the University of Cincinnati. Student work term evaluation characteristics will be correlated with data collected separately from employers on the relative importance of specific work characteristics within their industry. Additionally, we will collect self-assessments of performance from the students. We anticipate that this information will be useful for learning assessment evaluations, accreditation issues, and curriculum development.

Introduction

The Purdue University Office of Professional Practice is in a unique position to collect data applicable to the outcomes-based performance of our undergraduate students that is aligned with ABET ${ }^{1,2}$ Criterion III a-k. Several other institutions with Co-Op and internship programs have utilized their students' undergraduate work experiences to help evaluate their respective curriculums. The University of Cincinnati and Iowa State University are the acknowledged leaders in this type of assessment. The proposed process at Purdue will utilize the better features of each of these institutions' systems and will adjust their procedures to meet our local needs and our faculty's assessment desires. Additionally, the process will be designed to be general enough that it can potentially be used to assess the outcomes-based performance of undergraduate students within our service learning and summer research programs. 
The Office of Professional Practice has recently moved to modernize its database and information processing systems. It was natural at that juncture to look at the means by which we assessed the performance of our students in the work place. The current system being utilized is a paper evaluation that is returned to the student's home department. Although this document attempts to provide a fair assessment of the student, it is fairly simplistic in its categorization of skills. It was certainly not designed to correlate in any way with the ABET ${ }^{1,2}$ Criterion III requirements. In fact, the only difference between the present forms being issued to the students and the ones issued to the current Director when he was a Co-Op student in the mid-1970's, seems to be the font in which the documents are printed. Additionally, in the Purdue de-centralized system, the responsibility for processing the data lies with the local academic department. Data sets are smaller, no comparison between majors is possible, and the priority given to analysis is low. Bringing the entire process back within the central office in an electronic form will not only eliminate these deficiencies, but will also improve the quality of information that can be derived from the data and the timeliness of the analysis. This paper is intended to give cooperative education and internship professionals an idea of the development path utilized at Purdue in planning and preparing to implement an outcomes-based assessment system.

The balance of this paper will examine the Purdue experience in developing an outcomes-based assessment applicable to our situation. The following section will provide background and examine the efforts of some of the acknowledged academic leaders in outcomes-based assessment and review their efforts to date. The next segment will present the needs of the Purdue Engineering College in an undergraduate work experience assessment system. An informal focus group made-up of some of the Associate Heads for Undergraduate Education, other parties interested in assessment, and the Director of Professional Practice produced the guidelines for the development of our system. Our proposed plans for implementation will be discussed in the subsequent section. This will include the mechanisms we plan to utilize and the safeguards associated with them. The next segment will examine how we tentatively propose to analyze the information we collect. Although this information will be primarily for internal use, our hope is that the techniques will be similar enough to other peer institutions that we may eventually be able to do some comparisons with other universities' results. The paper will close with a discussion of our projected timeline, the anticipated reaction of our academic units, and comments about the wider applicability of our assessment system.

\section{Background}

The ABET ${ }^{1,2}$ Criterion III a-k outcomes are notoriously general in their definitions. They consist of eight abilities, two knowledges, and one understanding. Because of these very general definitions, it is a difficult proposition to ask a supervisor to evaluate a student's performance. It is problematic to then compare one supervisor's evaluation of one student with another supervisor's evaluation of a different student. The Iowa State evaluation process as reported by Mickelson, et al ${ }^{5,6,7}$ recognizes this difficulty, and it avoids the problem by mapping the assessment of a specific successful 
outcome onto the achievement of specific competencies associated with that outcome. The fifteen ISU general competencies are: Analysis and Judgment, Communication, Continuous Learning, Cultural Adaptability, Customer Focus, Engineering Knowledge, General Knowledge, Initiative, Innovation, Integrity, Planning, Professional Impact, Quality Orientation, Safety Orientation, and Teamwork. Competencies are deemed to have been achieved when students perform very specific key actions. The advantage in this process is that different supervisors should be able to much more definitively state whether or not a student has performed certain specific key actions, when compared against whether or not they have mastered a very general educational-based outcome.

Iowa State University developed their assessment process through a partnership with Development Dimensions International. They collected what they considered to be 'critical incidents' that were characteristic of success in the workplace from a wide variety of professionals. They categorized these incidents and then linked the appropriate behaviors to the outcome criteria. The categorization was then rated by the professionals as to the level of necessity. The results from this process were used to create the ISU assessment instrument in use today. Engineering Career Services at ISU has now collected data on the performance of Professional Practice students in approximately 65 specific key actions and disseminated this information to their various academic units for five years. Attainment of the ABET ${ }^{1,2}$ Criterion III objectives is implied through the completion of all competencies associated with a particular outcome. The strength of the Iowa State system would seem to reside in the experimental design linking the specific key actions with the attainment of the general results.

In contrast, the instrument used by the Division of Professional Practice at the University of Cincinnati seems to be more directly tied to the ABET ${ }^{1,2}$ Criterion III parameters, although some of their characteristics correspond to the ISU competencies. Cedercreutz and Cates ${ }^{8}$ have recently revamped the student work session assessment process at Cincinnati, and under their revised system, they have also accumulated about five years worth of data. The eleven UC categories for assessment are: Communication, Conceptual and Analytic Ability, Learning Theory and Practice, Professional Qualities, Teamwork, Leadership, Technology, Design and Experimental Skills, Work Culture, Organizational Planning, and Work Habits. Additionally, they have defined $41 \mathrm{sub}-$ categories of more specific skills. Although these measures are more direct in their connection with ABET performance metrics and perhaps do not have the experimental design sophistication of the ISU system, the real strength of the Cincinnati process is in the analysis of their data.

Supervisors utilize a standard 5 point qualitative description of performance in the sub-categories. This allows a numeric assignment to the qualitative descriptions and conversion to quantitative indices. From these values, standard statistical methods can be used to evaluate the performance of individual students, a specific student cohort, a particular department's cadre, and the overall college's performance. Utilizing the mean result for a particular category gives an indication of the students' proficiency at a particular skill. Improvement (or deterioration) over time indicates the growth in student skills as they pass through the academic and practical learning processes. The standard 
deviation for the category gives an indication of the effectiveness of the educational process as applied to that skill. This combination yields valuable information about the overall students' learning experience that can be utilized to adjust curriculum, teaching styles, or course sequences. The University of Cincinnati has recently received a longterm FIPSE grant and will continue to refine their student evaluation techniques over the next few years.

Although there are numerous other institutions that have long and successful histories of assessment, Iowa State and Cincinnati accurately represent two very valuable segments of the modern assessment process. Both of these institutions have been very generous in sharing their processes and techniques through publications and private conversations. As the Purdue Office of Professional Practice began its due diligence in preparation for revamping its own student work session evaluation process, it decided to draw heavily from these acknowledged assessment leaders. We believe that the resulting proposed process is an effective combination of both systems that will meet our unique institutional needs.

Purdue Objectives

In the Purdue de-centralized practical education system, the usefulness and effectiveness of a system is dependent upon local departmental 'buy-in'. Therefore, following an initial collection of background material by the Director of Professional Practice and a presentation to the Professional Practice faculty governing committee, an ad hoc committee consisting of several Associate Heads for Undergraduate Education, an Assistant Director for the College of Engineering's Women in Engineering Program, and the Director was formed. Additionally, the Directors of EPICS (Purdue's service learning organization) and SURF (Purdue's summer undergraduate research learning organization) were consulted, along with some of the smaller departments' accreditation committees and several Associate and Assistant Deans of the College of Engineering. This group reviewed the technical literature from Cincinnati and Iowa State and identified the best practices from each.

The Purdue College of Engineering had recently been through a strategic process that identified the competencies that it wished to incorporate into the Purdue Engineer of the Future ${ }^{4}$. Many of these attributes are the same as the Cincinnati categories and the Iowa State competencies. Some values were identified from the NAE ${ }^{3}$ Engineer of 2020 publication, and additionally, some distinct items were suggested by Purdue's industrial partners. This resulted in a set of 24 competencies in three distinct groupings of Abilities, Knowledges, and Traits. Table 1 identifies the Purdue sets of competencies, and the Purdue mapping of these competencies into the ABET ${ }^{1,2}$ Criterion III requirements is shown in Table 2. The competencies map into the various ABET Criterion within a range between 2 correlations for Leadership and Integrity and 9 correlations for Continuous Learner. Conversely, the ABET Criterions contain between 4 competencies for (i) the ability to engage in lifelong learning and 18 competencies for (c) the ability to design systems, components, and processes for a specific need. 
Table 1 - The Purdue Engineering Student Competencies.

\begin{tabular}{|l|l|l|}
\hline \multicolumn{1}{|c|}{ Abilities } & \multicolumn{1}{c|}{ Knowledges } & \multicolumn{1}{c|}{ Traits } \\
\hline & & \\
\hline Communication & Analytical Skills & Adaptable \\
\hline Cultural Awareness & Engineering Fundamentals & Continuous Learner \\
\hline Global Perspective & Experimental Skills & Customer Focused \\
\hline Judgment & General Knowledge & Entrepreneurial \\
\hline Leadership & Holistic Integration & Initiative \\
\hline Planning \& Responsiveness to Change & Mathematical \& Scientific Foundation & Innovative \\
\hline Synthesis & Problem Solving \& Design Skills & Integrity \\
\hline Teamwork & Quality Appreciation & Safety Oriented \\
\hline
\end{tabular}

Table 2 - Mapping of Purdue Competencies onto ABET 2000 Criterion III Outcomes.

\begin{tabular}{|c|c|c|c|c|c|c|c|c|c|c|c|}
\hline ABET 2000 Criterion III & $\mathrm{a}$ & $\mathrm{b}$ & $\mathrm{c}$ & $\mathrm{d}$ & $\mathrm{e}$ & $\mathrm{f}$ & $\mathrm{g}$ & $\mathrm{h}$ & $\mathrm{i}$ & $\mathrm{j}$ & $\mathrm{k}$ \\
\hline \multicolumn{12}{|l|}{ Purdue Competencies } \\
\hline & & & & & & & & & & & \\
\hline Communication & & & $\mathrm{X}$ & $\mathrm{x}$ & $\mathrm{X}$ & & $\mathrm{x}$ & & & & \\
\hline Cultural Awareness & & & $\mathrm{X}$ & $\mathrm{X}$ & & $\mathrm{x}$ & & $\mathrm{X}$ & & $\mathrm{X}$ & $\mathrm{x}$ \\
\hline Global Perspective & & & $\mathrm{X}$ & $\mathrm{x}$ & & & & $\mathrm{x}$ & & $\mathrm{x}$ & \\
\hline Judgment & & $\mathrm{X}$ & $\mathrm{X}$ & $\mathrm{x}$ & $\mathrm{X}$ & $\mathrm{X}$ & & $\mathrm{X}$ & & $\mathrm{X}$ & \\
\hline Leadership & & & & $\mathrm{x}$ & & & $\mathrm{X}$ & & & & \\
\hline Planning \& Responsiveness to Change & & $\mathrm{X}$ & $\mathrm{X}$ & $\mathrm{x}$ & & & & & & & \\
\hline Synthesis & $\mathrm{x}$ & $\mathrm{X}$ & $\mathrm{X}$ & & $\mathrm{x}$ & $\mathrm{X}$ & & $\mathrm{X}$ & & & $\mathrm{X}$ \\
\hline Teamwork & & $\mathrm{x}$ & $\mathrm{X}$ & $\mathrm{X}$ & $\mathrm{X}$ & & & & & & \\
\hline Analytical Skills & $\mathrm{X}$ & $\mathrm{x}$ & $\mathrm{X}$ & & $\mathrm{X}$ & & & & & & $\mathrm{X}$ \\
\hline Engineering Fundamentals & $\mathrm{X}$ & $\mathrm{X}$ & $\mathrm{X}$ & & $\mathrm{X}$ & & & $\mathrm{x}$ & & & $\mathrm{X}$ \\
\hline Experimental Skills & $\mathrm{X}$ & $\mathrm{x}$ & $\mathrm{x}$ & & $\mathrm{x}$ & & $\mathrm{X}$ & & & & $\mathrm{X}$ \\
\hline General Knowledge & & & & & & $\mathrm{x}$ & $\mathrm{X}$ & $\mathrm{x}$ & & $\mathrm{x}$ & \\
\hline Holistic Integration & $\mathrm{X}$ & $\mathrm{x}$ & $\mathrm{X}$ & $\mathrm{x}$ & $\mathrm{X}$ & & $\mathrm{x}$ & $\mathrm{x}$ & & & $\mathrm{X}$ \\
\hline Mathematical \& Scientific Foundation & $\mathrm{X}$ & $\mathrm{x}$ & & & $\mathrm{X}$ & & & & $\mathrm{x}$ & & $\mathrm{X}$ \\
\hline Problem Solving \& Design Skills & $\mathrm{X}$ & $\mathrm{x}$ & $\mathrm{X}$ & $\mathrm{X}$ & $\mathrm{X}$ & & $\mathrm{x}$ & & & & $\mathrm{X}$ \\
\hline Quality Appreciation & & $\mathrm{x}$ & $\mathrm{X}$ & & $\mathrm{x}$ & $\mathrm{X}$ & & & & & $\mathrm{X}$ \\
\hline Adaptable & & & & $\mathrm{x}$ & & & & $\mathrm{x}$ & $\mathrm{x}$ & & $\mathrm{x}$ \\
\hline Continuous Learner & $\mathrm{x}$ & $\mathrm{X}$ & $\mathrm{x}$ & & $\mathrm{x}$ & $\mathrm{x}$ & & $\mathrm{x}$ & $\mathrm{x}$ & $\mathrm{X}$ & $\mathrm{X}$ \\
\hline Customer Focused & & $\mathrm{x}$ & $\mathrm{X}$ & $\mathrm{x}$ & $\mathrm{X}$ & & $\mathrm{X}$ & & & & \\
\hline Entrepreneurial & & & & $\mathrm{x}$ & & $\mathrm{X}$ & $\mathrm{X}$ & $\mathrm{X}$ & & & \\
\hline Initiative & $\mathrm{X}$ & $\mathrm{X}$ & $\mathrm{X}$ & $\mathrm{x}$ & $\mathrm{x}$ & & $\mathrm{x}$ & & $\mathrm{x}$ & & \\
\hline Innovative & & $\mathrm{X}$ & $\mathrm{x}$ & & $\mathrm{x}$ & & & & & & \\
\hline Integrity & & & & $\mathrm{X}$ & & $\mathrm{X}$ & & & & & \\
\hline Safety Oriented & $\mathrm{x}$ & $\mathrm{x}$ & $\mathrm{X}$ & & $\mathrm{X}$ & & & & & $\mathrm{x}$ & $\mathrm{X}$ \\
\hline
\end{tabular}


The ISU experimental design was felt to have a distinct advantage in disconnecting the evaluation item from the outcome metric, so the development of associated key actions lists for each competency was completed. Unfortunately, this resulted in $128 \mathrm{key}$ actions for the set of 24 competencies. It was decided that few supervisors would wish to complete an evaluation with that many individual questions. Some form of reduction for at least the supervisor piece was clearly required.

At the same time it was recognized that an individual supervisor's viewpoint might not necessarily represent the view of an organization or industry as a whole, and there was a desire to retain at least a portion of the information represented by the larger key action set. It was also felt that valid information can be collected from the student side of the experience. The decision was therefore made to collect varying data from the human resources departments of our accredited employers, the Professional Practice students' direct work term supervisors, and the students themselves. Under this scheme, the length of the survey instruments and the frequency of administration could also be varied as is needed and as is appropriate.

Implementation

Purdue University qualifies all employer host organizations by academic discipline prior to allowing undergraduates to work at their locations. This process has been recently electronically automated, and some of the details have been previously reported by Stwalley ${ }^{9,10}$. The qualification process currently consists of collecting certain critical contact information from the potential employer and collecting certain employment specific information of interest to students considering working for the organization. The potential employers also provide a typical work plan for students within the organization's training program to be used by our faculty in evaluating the quality and technical applicability of the proposed program. After the work plan is approved, we get an authorized representative from the organization to sign Purdue's Statement of Understanding that outlines our expectations for the educational program with that organization. In practice, our experience tells us that this process is almost always completed within the potential host organization's Human Resources department. This makes this process an excellent venue to collect general information from the organization about the importance of the various Purdue attributes to the organization and the necessity of an individual's ability to perform certain key actions to their potential success within that organization. Therefore, we have devised an employer instrument that will ask an HR representative to rank the eight competencies in each of the three groups (Abilities, Knowledges, and Traits) from the most important to least important for that specific discipline in a recent graduate. The respondents are then asked to evaluate key actions associated with each competency as to whether they are necessary, useful, or non-useful in a recent graduate of that same academic discipline. Additionally, the HR representatives are given the opportunity to add other essential key actions not listed. Since Purdue Professional Practice employers are qualified for specific disciplines, the survey instrument should collect unique results for each academic major. We understand that the results of this particular survey instrument may lose their significance with time, and therefore, our intention is to create a mechanism to periodically refresh this data. 
Our employers are presently asked through our electronic system to re-acknowledge the Purdue Statement of Understanding each year prior to recruiting for our annual Co-Op Days event. Our intention is to add this survey instrument to the re-acknowledgement function on a biannual basis to track changes in overall employer requirements over time. Employers will be unable to recruit students without completing this survey instrument.

The individuals that directly supervise our students on their work assignments are in a position to provide different information. In comparison with the general requirements of the organization, supervisors have specific knowledge of a specific student's performance within their section. This will vary by individual and will vary over time as the student progresses in their education and on to different work stations within the program. Direct supervisors will be asked to evaluate the student's performance following each work period using a traditional dot scale that can be assigned a numeric value for each of the 24 Purdue competencies. The evaluation benchmark will be the level of performance expected in a newly hired graduate within the student's discipline. The descriptions of performance and their associated numeric basis are:

$\begin{array}{ll}\text { No Basis for Evaluation } & 0 \\ \text { Beginning } & 1 \\ \text { Developing } & 2 \\ \text { Achieving } & 3 \\ \text { Accomplished } & 4 \\ \text { Exemplary } & 5\end{array}$

A rating of three or higher will indicate that a student has achieved a satisfactory performance level within a specific competency. When a student performs satisfactorily on all competencies mapped back into an ABET III a-k criterion, they will be deemed to have minimally met that criterion. Supervisors will be given the opportunity to provide additional comments on the student's performance and to provide an overall numeric evaluation between 0 and 10 . It will be the student's responsibility to see that the supervisor completes the electronic performance evaluation instrument for the specific work term. Failure to complete the evaluation will result in an unsatisfactory grade on the Professional Practice course for that term. Multiple term data on individual students should provide a redundancy or repeatability in the measurement of achievement for a student's competency in a particular area, and it should also allow the tracking of growth in the performance of that competency, since the performance benchmark will be constant at that of a just completed Bachelor's level employee.

Students will also be asked to evaluate their performance using the same basis as the supervisor, and the differential between the student's self-evaluation and their supervisor's will indicate perceptive gaps in the student's overall learning achievement. Students will also be asked to examine the list of key actions associated with the various competencies and indicate whether they were given an opportunity to perform any of the key actions. Additionally, students will be asked other historical Purdue Co-Op questions regarding their relationship with the group and supervisor, the understanding displayed by the organization of the educational goals of the work experience program, and the 
work term evaluation feedback provided by the supervisor. Again, it will be the student's responsibility to complete this electronic evaluation instrument as a requirement of the work experience course, and again, failure to complete the process will result in an unsatisfactory grade.

\section{Projected Analysis}

The three different survey instruments will collect different types of information and will need to be analyzed in different ways, but in all cases the end customer of the various analyses will be the Purdue College of Engineering administration and academic departments. The purpose of the general employer survey instrument is to gauge the need on the part of employers for the various Purdue competencies within the specific academic disciplines. It is certainly conceivable that recruiters for one branch of engineering may have different priorities than recruiters for another. Further, we also recognize that these priorities may change with time, so we anticipate an annual report on this data.

Respondents of the employer survey instrument will be asked to rank the eight competencies from their most important to their least. A weighted average will be computed for each of the three categories assigning one point to the most important item and eight to the least. The sum total of each individual competency will be divided by the sample size, and the list will then be ranked from top to bottom. This list should then provide the academic units with a relative importance level that industrial recruiters within their discipline attach to the various competencies. We anticipate that this information will be useful to the academic departments as they examine their overall degree programs and course syllabuses.

Employer representatives will also be asked to evaluate specific key actions that relate to the utilization of the various competencies. A simple three point scale of Essential, Useful, and Unnecessary will be used by employers to evaluate the key actions. We will report the percentage of employers that rank the specific key action under each classification. This information is anticipated to be more useful to individual instructors as they plan the elements of their courses. Practice at essential items would obviously want to be emphasized, while performing unnecessary items could be eliminated. In either case, the information provided by this feedback mechanism from industry should prove useful to both the administration and the faculty within the various academic departments.

Although these instruments will have importance to the departmental Faculty Coordinator for counseling students and judging the effectiveness of various organizations' work experience programs, the combined supervisors' surveys will be most useful to the departments in their ABET accreditation process and in reviewing their teaching effectiveness. New information regarding student performance in the work place will become available at the conclusion of each academic term. Therefore, this information will be analyzed and reported three times per year. The Cincinnati analysis scheme will be used initially to examine the aggregate data. Student performance will be 
measured as they progress through each of the successive work sessions, and this will allow a calculation of their growth in performance rating for the various competencies. The average numeric value of the students' performance on a particular competency will provide an indication of the general level of a cohort's ability to utilize that competence in practice. It may be assumed that the higher the overall value of the performance rating, the better the environment being provided by the department to facilitate the cultivation of that competence. Temporal tracking of the performance ratings should indicate the growth of a cohort's ability to practice a competency. Since the evaluations are to be made relative to a fixed benchmark, a decrease in rating would clearly indicate that there was some type of dysfunction in the educational process. The standard deviation of the aggregate data of a particular cohort is an indication of the effectiveness of the educational process. A small deviation indicates an effective process, and a large deviation shows an inefficient process that reaches some students, but not all.

Plots of average performance rating against variance for each competency will provide the departments with information regarding how well they are meeting the students' educational needs as evaluated by the outcomes competencies. If the plot is divided into quadrants based upon the median values, the placement of the data set within each quadrant of the chart will indicate a different potential action. High average value and low deviation indicates the best performance for the learning experience.

Competencies in this quadrant are being taught with best practices, and these techniques should be emulated. High average value and high deviation means that the learning experience, while fairly good, is not reaching all students uniformly. Most students are doing fine in the specific learning environment, while others are missing information. Some corrective action is needed to insure that all students have the opportunity to learn the material. A low average and a high deviation indicate that most students are not learning the material, but there is some effective teaching for a smaller segment of the population. Some portions of the present instructional system for that competency may be salvaged, but significant improvement in the material delivery system is required to reach more students effectively. The worst condition is low average score and low deviation. In this case, a uniformly poor job of presenting material for all students is being done. This calls for a complete overhaul of the techniques utilized to teach these competencies. This matrix should prove valuable to the academic departments by providing a means to review their effectiveness in teaching the Purdue competencies.

Another measure of teaching effectiveness will be the translation of competency proficiency into the ABET matrix. Students that achieve a rating of three or higher on a particular competency are deemed to have minimally mastered that competency. When a student has achieved mastery of all the competencies mapped into an ABET outcome, they are deemed to have successfully met the requirements of that outcome. The level of students reaching proficiency within an ABET outcome will be tracked, and this information can then be additionally utilized by the administration and faculty to adjust the curriculum and teaching techniques within the various academic departments.

Supervisor's individual evaluations will be available to both the student and their Faculty Coordinator. This will be of use in counseling the student and helping them to 
self-reflect upon the previous term's practical learning experience. Additionally, Faculty Coordinators will have access to the student's evaluation of the work term. Differentials between the supervisor and the self-evaluation should provide indications of perceptive error on the part of either the student or supervisor. While the Faculty Coordinator will have to engage in a credibility evaluation at this point, the information provided will certainly identify areas of concern for the individual. Over time, it will be possible for the Faculty Coordinators to track the students' growth in becoming proficient at the various competencies. This information should be useful to the individual student in planning future course work and work assignments. In the aggregate, perceptive differences between the supervisor and student evaluations may also indicate areas of educational need. Student reporting on the availability of opportunities to perform specific key actions can provide an indication of which experiences are adequately covered by work terms and which experiences need opportunities to be included within the traditional academic environment. Since the three survey instruments will be collecting a rich and diverse set of data, we fully expect that there will be additional inferences and corrective measures that can be developed, once we fully develop the system and realize its true potential.

\section{Close}

Experiential activities within the undergraduate curriculum can clearly provide a means to evaluate students' learning outcomes prior to their leaving the institution. In our assessment process, these learning outcomes are tied to the achievement of general competencies through the execution of specific key actions on the part of the student. The process proposed by the Purdue University Office of Professional Practice for implementation collects data from three different sources to evaluate the overall effectiveness of the Purdue educational process. A general employer survey instrument will rate the various Purdue competencies on their value to industry and identify the key actions selected as most crucial by actual employers within specific disciplines. Individual supervisors will evaluate the students' performance in the work place, and the aggregate data collected from this instrument will measure the growth in learning outcomes for various cadres of students and track their change in learning performance over time. This information should prove invaluable in meeting ABET's requirements of establishing a culture of continuous improvement, and it should be an additional source of evidence toward supporting our claim of a positive educational process performance from our students in Professional Practice. Information collected from students will be useful in evaluating perceptive differences in learning outcomes and assisting Faculty Coordinators with student counseling.

The current rollout schedule for the Purdue University Professional Practice outcomes-based assessment process is tentative based upon final approval by the ad hoc Professional Practice assessment development committee. We currently anticipate that the general employer survey instrument will "go live" during the spring of 2007, and the supervisor and student survey instruments will become operational in the summer of 2007. Although we believe that the general faculty support of detailed assessments of students' work experiences will be mild initially, administrative and departmental accreditation 
committee support will be strong. The level of support from these groups has been very strong during the creation of the new system. It is our belief that general faculty support will follow, once it is shown how useful and valuable the data can be. Although the experimental design has changed and the data collection is more extensive, it can easily be asserted that the proposed system is merely a modern, electronic, better-designed version of our existing evaluation system. By any consideration, being better aware of the outcomes of a particular process allows for improved reflection and adjustment. We firmly believe that this system will meet the current needs of our administration and faculty and that it has the flexibility and capability to be dynamic and meet those needs in the future as well.

\section{References}

1) Accreditation Board for Engineering and Technology, "Criteria for Accrediting Engineering Programs Effective for Evaluations During the 2000-2001 Accreditation Cycle", (ABET, 2000).

2) Accreditation Board for Engineering and Technology, "Criteria for Accrediting Engineering Programs Effective for Evaluations During the 2007-2008 Accreditation Cycle”, (ABET, 2006).

3) Mickelson, S.K., Hanneman, L.F., \& Brumm, T., "Validation of Workplace Competencies Sufficient to Measure ABET Outcomes", Proceedings of the 2002 American Society for Engineering Education Annual Conference \& Exposition, (ASEE, 2001).

4) Mickelson, S.K., Hanneman, L.F., Prignitz, L.K., \& Lehman, M., "Constituent-Created, CompetencyBased, ABET-Aligned Assessment Tools for the Engineering Experiential Education Workplace", Proceedings of the 2002 ABET Annual Meeting - National Conference on Outcomes Assessment for Program Improvement, (ABET, 2002).

5) Mickelson, S.K., Hanneman, L.F., Brumm, T.J., \& Steward, B.L., "Using Engineering Competency Feedback to Assess Agricultural Engineering Curriculum”, Proceedings of the 2003 American Society for Engineering Education Annual Conference \& Exposition (ASEE, 2003).

6) Cedercreutz, K. \& Cates, C., "Using Statistical Analysis of Co-Op Student Work Term Performance in the Assessment of Cooperative Education Curricula: Proof of Principle", Proceedings of the 2006 UC/FIPSE Symposium, (CEIA, 2006).

7) Purdue University College of Engineering, "Purdue Engineer of the Future", internal strategic document, 2005.

8) National Academy of Engineering, Educating the Engineer of 2020, (The National Academic Press, 2005).

9) Stwalley III, R.M., "Survival and Success in Co-Op Programs Through Market Analysis and Core Values", Proceedings of the 2006 Cooperative Education and Internship Association Annual Meeting, (CEIA, 2006).

10) Stwalley III, R.M., "Definition, Mission, and Revitalization of Cooperative Education Programs", Proceedings of the 2006 American Society for Engineering Education Annual Conference \& Exposition (ASEE, 2006). 